\title{
Circadian rhythms of S-IgA and cortisol in whole saliva -Compensatory mechanism of oral immune system for nocturnal fall of saliva secretion-
}

\author{
Tetsuo Shirakawa, Masato Mitome* and Haruhisa Oguchi* \\ Center for Advanced Oral Medicine, Hokkaido University Hospital \\ Kita-13, Nishi-6, Kita-ku, Sapporo 060-8586, JAPAN \\ * Pediatric Dentistry, Graduate School of Dental Medicine, Hokkaido University \\ Kita-13, Nishi-7, Kita-ku, Sapporo 060-8586, JAPAN
}

\begin{abstract}
Secretory immunoglobulin A (S-IgA) plays the major role for protecting mucosal tissue from infection, and its level in saliva is thought to be the indicator of immune function in the oral cavity. In the present study, we measured the levels of S-IgA, cortisol and total protein in whole saliva as well as flow rate in healthy young adults $(\mathrm{n}=8)$ throughout a 24-hr period, and found that salivary S-IgA, cortisol and flow rate fluctuated in a circadian manner with their acrophases (peak time of the rhythms) at 06:50h, 09:04h and $19.01 \mathrm{~h}$, respectively $(P<0.05)$. Mesor (midline estimating statistics of rhythm) of the three rhythms was $0.30 \mathrm{mg} / \mathrm{ml}$ for $S-\operatorname{IgA}, 8.56 \mathrm{ng} / \mathrm{m} l$ for cortisol, and $0.47 \mathrm{ml} / \mathrm{min}$ for the flow rate. The acrophase of S-IgA rhythm corresponded to the nadir of the flow rate rhythm, indicating that these two rhythms are anti-phase to each other. We suggest that the circadian rhythm of S-IgA is not simply subject to daily fluctuation of the volume of salivary fluid that dilutes S-IgA, but is influenced directly or indirectly by central circadian pacemaker, because the ratio of S-IgA to total protein in the morning is more than 3 times higher than that in the evening. The elevation of S-IgA concentration in saliva from midnight to early morning may indicate compensatory mechanism of oral immune system to the fall of saliva secretion during sleep.
\end{abstract}

\author{
Key words \\ Circadian rhythm, \\ Cortisol, \\ Flow rate, \\ Saliva, \\ Secretory IgA
}

\section{Introduction}

Many physiological parameters fluctuate in a 24-hr period and such variation is defined as circadian rhythm ${ }^{1,2)}$. Among them, flow rate of unstimulated saliva has been shown to fluctuate in a circadian manner with its peak in the late afternoon ${ }^{3)}$ or in the evening $^{4)}$ and trough in the early morning ${ }^{3,4)}$. There are individual variations of saliva secretion and differences in composition between under resting and stimulated conditions ${ }^{5,6)}$. Saliva secretion is closely related with sleep-wake cycle and the flow

Received on October 6, 2003

Accepted on January 5, 2004 rate declines to nearly zero level during sleep ${ }^{3)}$. It is well known that the nocturnal fall of saliva secretion reduces mechanical washing in the oral cavity and increases susceptibility to dental caries.

One of the most important indicators of local immune system in the oral cavity is secretory immunoglobulin A (S-IgA), which can reduce the adherence of microorganisms to the tooth surface and oral mucosa ${ }^{7,8)}$. It has also been stated that S-IgA plays a significant role in maintaining homeostasis in oral microbial populations ${ }^{7)}$. A recent study has demonstrated that the concentration of $S-\operatorname{IgA}$ in saliva changes rapidly after awakening; S-IgA is remarkably high at the time of awakening and falls subsequently ${ }^{9}$. The S-IgA decline is correlated with 
the rise of cortisol, a humoral marker of stress response associated with activation of hypothalamic-pituitaryadrenal (HPA) axis, which may suggest relationship between the local immune system involving S-IgA and central neuroendocrine pathway ${ }^{9}$.

The rise of cortisol level in the morning is under the regulation by the central circadian pacemaker localized at the suprachiasmatic nucleus $(\mathrm{SCN})^{10,11)}$. The SCN is found in all mammals bilaterally in the anterior hypothalamus immediately above the optic chiasm ${ }^{10}$. It is composed of densely-packed parvocellular neurons, and lesions of the SCN result in the loss of behavioral, endocrinological, immunological and physiological circadian rhythms ${ }^{2}$. In particular, SCN lesions cause a random distribution of sleep bouts over the 24-hr period ${ }^{2)}$. However, it is yet unclear whether the dynamic change in $\mathrm{S}$ $\operatorname{IgA}$ after awakening is regulated by the circadian pacemaker or not. In the present study, we measured fluctuations of salivary flow rate, $\mathrm{S}-\operatorname{Ig} \mathrm{A}$, cortisol and total protein in unstimulated whole saliva in healthy subjects throughout a 24-hr period, and analyzed their circadian rhythms by Cosinor test ${ }^{1)}$.

\section{Materials and methods}

\section{Subjects}

Following approval by the local ethics committee, 8 volunteers (6 males and 2 females, age: $24-29)$ gave us informed consent to participate in the study. All were in good health, free of medication and non-smokers. Each subject was given a package containing sterilized cotton rolls, $15 \mathrm{ml}$ centrifuge tubes (Corning, NY, USA) and written instructions. They were all briefed concerning the collection procedure and were asked to keep daily schedule of waking up at 7:00 and going to sleep at 24:00 for 2 days before the day of saliva collection.

\section{Collection of unstimulated whole saliva}

On the day of saliva collection, the subjects were asked to wake up at 7:00 and to collect saliva intermittently for $24 \mathrm{hrs}$ at 12:00, 16:00, 20:00, 24:00, 04:00, 08:00, 12:00 h in their homes. They were allowed to sleep between 24:00 and 7:00 except for the time of saliva collection at 04:00. Unstimulated whole saliva was collected for an accurately-timed $5 \mathrm{~min}$ period by placing dental cotton rolls on the floor of the mouth. They withdrew the cotton rolls when the rolls fully absorbed saliva, and put new rolls immediately at the same position.
After each sampling, all the rolls were collected, put in centrifuge tubes, sealed and refrigerated at $4^{\circ} \mathrm{C}$. Meals and drinks were given within $1 \mathrm{hr}$ after the saliva collections throughout the experimental period to reduce any possible effects on the saliva samples. After collection, the samples were transported immediately to our laboratory and stored at $-20^{\circ} \mathrm{C}$ until the assay.

\section{Assay procedures}

The samples were thawed by centrifugation at 3,000 r.p.m. for $10 \mathrm{~min}$ and the saliva was collected in plastic vials. The volume of each sample was measured by using precision microliter pipettes (Pipetman, Gilson, Villiers-le-Bel, France) of 2 volume ranges (20-100 $\mu l$ and 200-1000 $\mu l$ ). Then, they were passed through a Millipore filter of $0.45 \mu \mathrm{m}$ to eliminate contaminated debris and microorganisms.

The S-IgA levels in the saliva samples were determined by ELISA as follows: 96-well polystyrene plates were coated overnight at $4^{\circ} \mathrm{C}$ with goat anti-human $\operatorname{IgA}(5 \mu \mathrm{g} / \mathrm{ml}$, Tago, Burlingame, CA, USA), blocked with PBS containing 5\% BSA for $1 \mathrm{hr}$ at $37^{\circ} \mathrm{C}$, and incubated for $1 \mathrm{hr}$ with the test samples (1:5,000 dilution in PBS containing 0.05\% Tween 20) and S-IgA standards diluted in PBS. Those samples that exceeded the upper limit of the standard range $(0-0.5 \mathrm{mg} / \mathrm{ml})$ were adjusted by further dilution. Goat anti-human S-IgA conjugated to horseradish peroxidase (Cappel Division of Organon Teknika, Durham, NC, USA) was added after washing. Hydrogen peroxide with o-phenylenediamine dihydrochloride was used for color development. The reaction was stopped by adding $2 \mathrm{~N}$ sulfuric acid, and the plates were read at $490 \mathrm{~nm}$. For each ELISA all the samples were read on the same day to eliminate day-to-day variation.

Saliva cortisol levels were determined by using Cortisol Radioimmunoassay Kit (Commissariat al'energie atomique, France) developed for the measurement of cortisol in serum or plasma. This assay is based on the competition between unlabelled cortisol and a fixed quantity of ${ }^{125} \mathrm{I}$-labelled cortisol for a limited number of binding sites on cortisolspecific antibody coating the inner surface of plastic tubes. In brief, $100 \mu l$ of each saliva sample was mixed with $500 \mu l$ of ${ }^{125}$ I-labelled cortisol, and the mixed solution was added to the reaction tube and incubated overnight at room temperature. After aspiration of the aqueous solution, the radioactivity of the reaction tube was measured by using a scintillation 


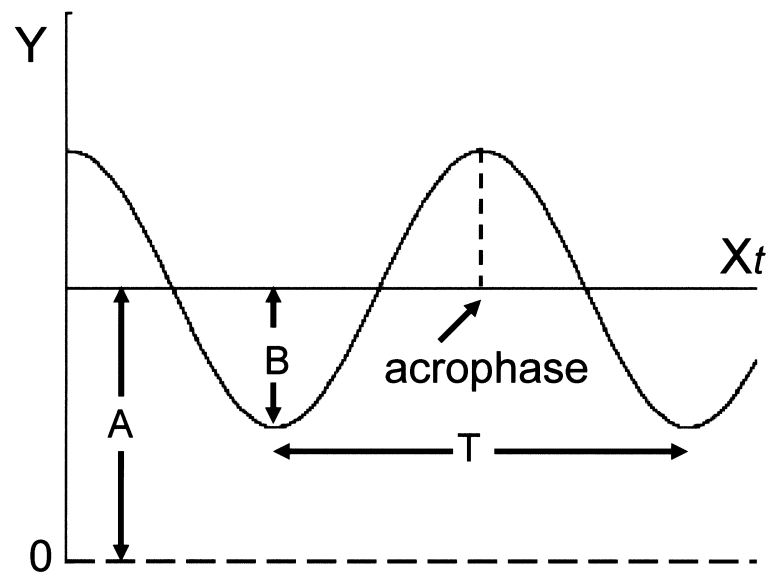

Fig. 1 Parameters of circadian rhythm

To estimate these parameters, Cosinor test was applied to the group data. The measured variable $(\mathrm{Y})$ is a function of the time of observation $\left(\mathrm{X}_{\mathrm{t}}\right)$ as represented by the following formula.

$$
\mathrm{Y}=\mathrm{A}+\mathrm{B} \cos \left(2 \pi \mathrm{X}_{\mathrm{t}} / \mathrm{T}+\psi\right)
$$

Here, A indicates a mesor, $\mathrm{B}$ an amplitude, $\psi$ a phase-angle to an appropriate reference and $\mathrm{T}$ a period $(=24.0 \mathrm{hrs})$.

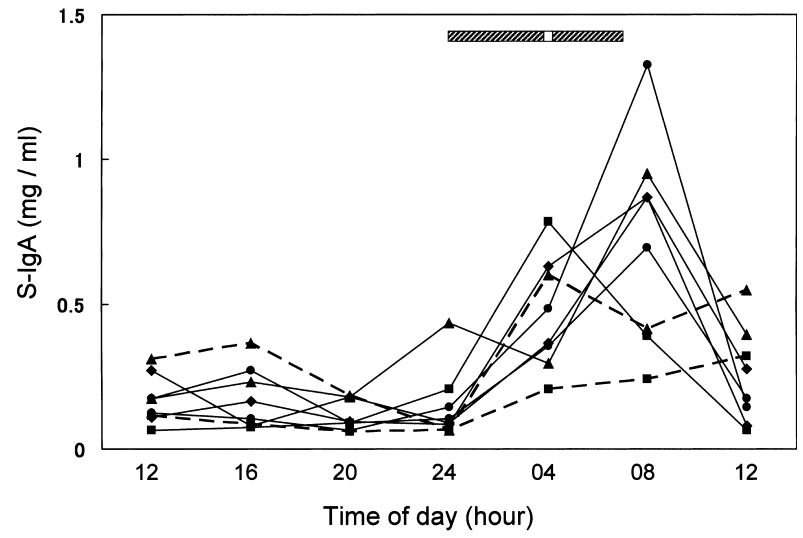

Fig. 2 Circadian variation in salivary S-IgA concentrations in healthy subjects $(n=8)$

The horizontal bar represents sleep spans that include a short awakening period at 4:00 for saliva sampling. S-IgA fluctuations of two subjects with persistently high S-IgA levels at 12:00 on the second day are shown by dotted lines.

Table 1 Circadian rhythm parameters for S-IgA, cortisol, total protein, S-IgA/protein and flow rate

\begin{tabular}{lccccc}
\hline & Mesor & Amplitude & Acrophase (clock time) & Group rhythm (Cosinor) & ANOVA \\
\hline S-IgA $(\mathrm{mg} / \mathrm{m} l)$ & $0.30 \pm 0.20$ & $0.27 \pm 0.16$ & $06: 50 \pm 01: 37$ & $P<0.05$ & $P<0.001$ \\
Cortisol $(\mathrm{ng} / \mathrm{m} l)$ & $8.56 \pm 3.42$ & $2.72 \pm 2.65$ & $09: 04 \pm 02: 13$ & $P<0.05$ & $P<0.001$ \\
Total protein $(\mathrm{mg} / \mathrm{m} l)$ & $3.53 \pm 1.84$ & $0.97 \pm 1.96$ & $07: 08 \pm 01: 27$ & n.s. & $P<0.05$ \\
S-IgA $/ \mathrm{TP}(\%)$ & $8.14 \pm 8.10$ & $4.64 \pm 6.02$ & $07: 16 \pm 01: 01$ & n.s. & $P<0.05$ \\
Flow rate $(\mathrm{m} l / \mathrm{min})$ & $0.47 \pm 0.31$ & $0.10 \pm 0.04$ & $19: 01 \pm 01: 32$ & $P<0.05$ & $P<0.01$ \\
\hline
\end{tabular}

Results of a Cosinor test are shown as mean \pm confidence limit. Mesor: midline estimating statistics of rhythm ${ }^{1)}$

counter. Total salivary protein was determined by the method of Lowry et al. ${ }^{12)}$ with a bovine serum albumin standard at the concentration of $0.02-$ $0.25 \mathrm{mg} / \mathrm{ml}$. The saliva samples were diluted to $1: 50$ with PBS before the protein assay.

\section{Data analysis}

Circadian rhythms of S-IgA, cortisol, total protein, $\mathrm{S}-\mathrm{IgA} /$ total protein ratio and flow rate of whole saliva were analyzed by a Cosinor test and one-way ANOVA for repeated measures, followed by Tukey's $t$-test. By using the Cosinor test, we obtained the best-fitting cosine wave to the series of data in a 24-hr cycle, which enabled determination of a mesor, an amplitude and an acrophase (Fig. 1).

\section{Results}

Cosinor test for the concentrations of salivary S-IgA and cortisol and the flow rate revealed significant circadian rhythm $(P<0.05)$. Table 1 indicates that the acrophase (peak time of the rhythm) of S-IgA appeared at 06:50h. The acrophase of S-IgA in the early morning was opposite to that of the flow rate with a phase angle difference of about $12 \mathrm{hrs}$, and preceded that of cortisol by $2 \mathrm{hrs}$. Figure 2 indicates the fluctuation of individual S-IgA values in eight subjects over 24-hr period. Each of the individual S-IgA rhythms showed a dramatic elevation in its level at 04:00 or 08:00 and most of them returned to the basal level at 12:00. 

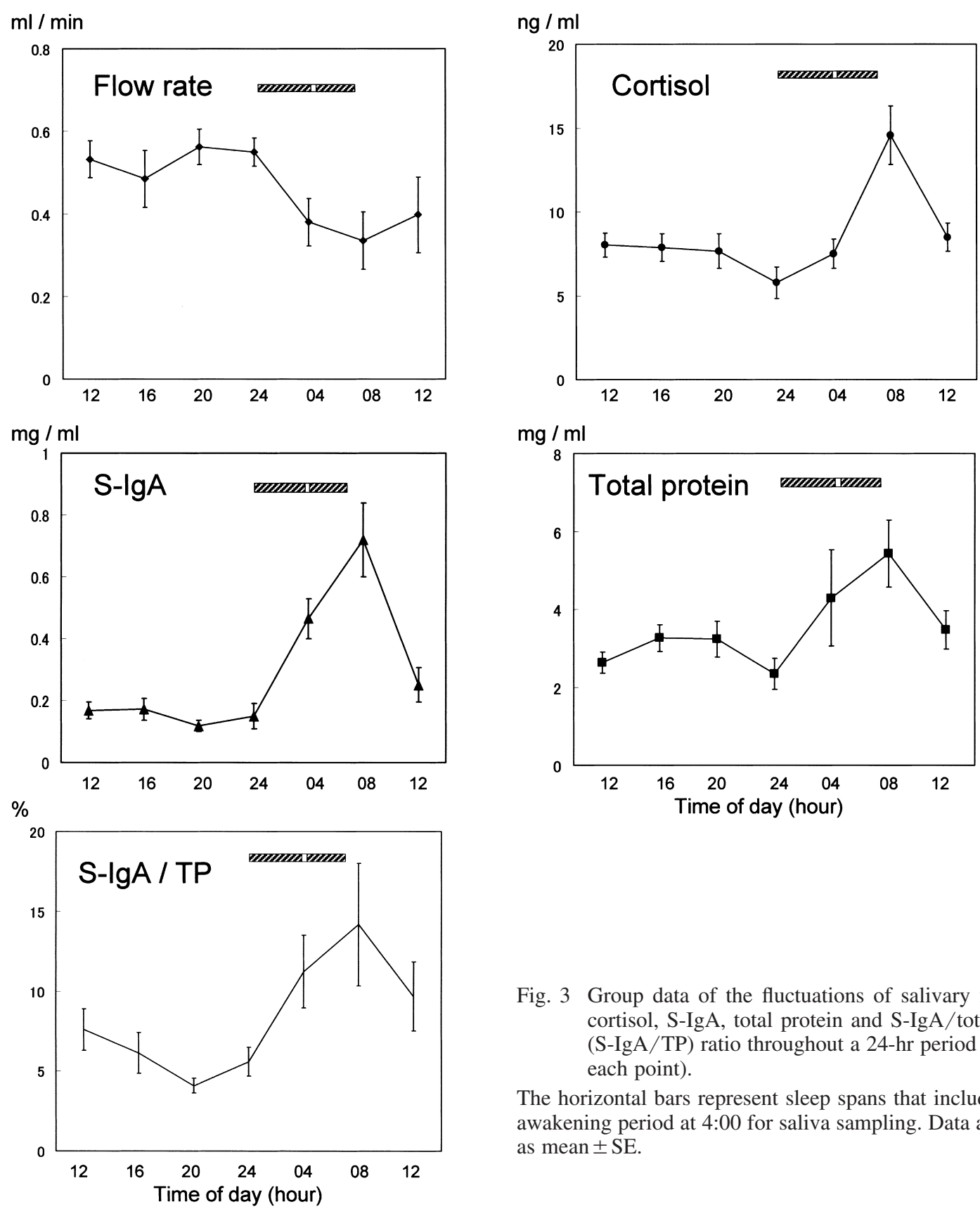

Fig. 3 Group data of the fluctuations of salivary flow rate, cortisol, S-IgA, total protein and S-IgA/total protein $(\mathrm{S}-\mathrm{IgA} / \mathrm{TP})$ ratio throughout a $24-\mathrm{hr}$ period $(\mathrm{n}=8$ for each point).

The horizontal bars represent sleep spans that include a short awakening period at 4:00 for saliva sampling. Data are shown as mean $\pm \mathrm{SE}$.

Group data of S-IgA, cortisol, total protein, S$\operatorname{IgA} /$ total protein ratio and flow rate of whole saliva are indicated in Fig. 3. As revealed by Cosinor test, S-IgA, cortisol and flow rate clearly show circadian rhythms, and the levels of S-IgA and cortisol are highest at 08:00 and the flow rate is lowest at 08:00. Although the circadian fluctuations of total protein and $\mathrm{S}-\operatorname{Ig} \mathrm{A} /$ total protein ratio are not statistically significant in Cosinor test (Table 1), both levels are high at 8:00 and low at night and the fluctuations

are significant in repeated measures ANOVA. The $\mathrm{S}-\mathrm{IgA} /$ total protein ratio at 08:00 was more than 3 times higher than that at 20:00.

\section{Discussion}

\section{Circadian rhythms of salivary S-IgA, cortisol and flow rate}

The presence of circadian rhythm in salivary flow rate and cortisol has been described by a number of 
researchers ${ }^{3-6,13-15)}$. These rhythms are under the control of the circadian pacemaker localized at the $\mathrm{SCN}$ which is also known as a master pacemaker for sleep-wake rhythms ${ }^{2}$. The 24-hr cycle of cortisol has been shown to undergo a phase shift when sleep-wake rhythms are altered by daytime sleep and nighttime work ${ }^{16}$. The flow rate rhythm is directly regulated by sleep-wake rhythms through autonomic nervous system; and as we have observed in our study, both cortisol and flow rate showed significant circadian rhythms (Table 1). Therefore, the majority of the subjects seem to have adapted themselves to the sleep-wake schedule (going to sleep at 24:00 and waking up at 7:00) imposed just prior to the experiment.

The most important finding in the present study is the circadian rhythm of S-IgA in whole saliva revealed by collecting saliva samples throughout 24-hr period. In comparison of the group data, the $\mathrm{S}-\operatorname{Ig} \mathrm{A}$ concentration at 08:00 is more than 4 times higher than the level at 20:00. Total amount of S-IgA in the whole saliva collected for a $5 \mathrm{~min}$ period also showed significant rhythm, and acrophase of the rhythm was almost identical with that obtained from S-IgA concentration (data not shown). There might be an influence of the interruption of sleep at 04:00 for saliva collection upon the S-IgA level in two subjects as shown by the persistently high S-IgA levels at 12:00 on the second day (Fig. 2). Nevertheless, statistical analysis of the group data does not show a significant difference in S-IgA level between the samples collected at 12:00 on the first day and those at the same hour on the second day. Since the cortisol levels at 12:00 are almost the same on the first and second days (Fig. 3), the short interruption of sleep at 04:00 seems to have no substantial effect either on the central circadian pacemaker or on the grouped S-IgA rhythm.

\section{Salivary S-IgA rhythm is influenced by central circadian pacemaker}

As shown in Table 1 and Fig. 3, the peak of S-IgA coincides with the trough of flow rate, and the trough of S-IgA coincides with the peak of flow rate, indicating negative correlation between the two rhythms. Similar temporal relationship is found between the total protein and the flow rate, although the total protein did not show significant rhythm in Cosinor test. These results may suggest that the production of S-IgA is constant throughout a day and the circadian change in the volume of salivary fluid causes S-IgA rhythm. However, this is not likely because the ratio of $S$ - $\operatorname{IgA}$ to total protein varies with time and the ratio at 08:00 is more than 3 times higher than that at 20:00.

It was shown in a recent study that circadian oscillators reside not only in the SCN but also in most peripheral tissues ${ }^{17}$. In a steady state, these peripheral oscillators are synchronized by the central circadian pacemaker in the SCN. In fact, inductions of circadian gene expression and transient changes in the phase of circadian gene expression have been recognized in liver, kidney, heart and other organs. It is possible that the production of S-IgA by plasma cells and/or the transepithelial transport of S-IgA from the basal to the luminar face of the epithelium ${ }^{18)}$ are regulated by peripherally expressed clock genes ${ }^{17,19)}$. Interestingly, the glucocorticoid hormone analog dexamethasone induces circadian gene expression in cultured rat-1 fibroblasts and transiently changes the phase of circadian gene expression in liver, kidney, and heart ${ }^{17}$. In mammary gland organ culture, cortisol decreases the expression of poly-Ig-receptor which is also known to be expressed in salivary gland epithelial cell $\mathrm{s}^{20)}$. Therefore, S-IgA rhythm may be caused by clock genes expressed in epithelial cells through daily changes in the transepithelial transport of S-IgA, and cortisol may modulate this process.

\section{Significance of salivary S-IgA rhythm for oral health}

The secretory immunoglobulins, IgA in particular, play important roles in the first line of defense for mucosa against pathogenic microorganisms. S-IgA can reduce the adherence of microorganisms to the tooth surface and oral mucosa ${ }^{7,8)}$, and patients deficient in salivary immunoglobulins have a higher caries incidence than those with normal salivary immunoglobulins ${ }^{21)}$. Therefore, the enhancement of $\mathrm{S}$-IgA concentration in saliva from midnight to early morning must contribute to the defense against cariogenic bacteria as well as against other pathogenic microorganisms in the oral cavity, and it can be interpreted as compensatory mechanism for the fall of saliva secretion.

Flow rate of saliva is closely related with oral health ${ }^{22)}$ and low caries rate has been reported in children with familial dysautonomia ${ }^{23)}$. Since flow rate of saliva declines during sleep ${ }^{3)}$, reinforcement of circadian rhythm of salivary S-IgA is considered to be extremely important for the oral health. In 
infants, $\mathrm{S}-\operatorname{Ig} \mathrm{A}$ levels in whole saliva is significantly lower than those in young adults ${ }^{24}$. It should be emphasized to set a regular bedtime and wake-up time for children, which will facilitate establishment of circadian rhythm of salivary S-IgA.

\section{Acknowledgments}

We thank Dr. Ken-ichi Honma, Professor of the Department of Physiology, Hokkaido University Graduate School of Medicine, for helpful advice on the analysis of 24-hr rhythm.

\section{References}

1) Halberg, F., Tong, Y.L. and Johnson, E.A.: The Cellular Aspects of Biorhythms. Soringer, New York, 1967, pp. 20-48.

2) Aschoff, J. and Wever, R.A.: Handbook of Behavioral Neurobiology. Plenum Press, New York, 1981, pp. 311-331.

3) Dawes, C.: Circadian rhythms of human salivary flow rate and composition. J Physiol (Lond) 220: 529-545, 1972.

4) Ferguson, D.B. and Fort, A.: Circadian variations in human resting submandibular saliva flow rate and composition. Archs Oral Biol 19: 47-55, 1974.

5) Dawes, C.: Circadian rhythms in the flow rate and composition of unstimulated and stimulated human submandibular saliva. J Physiol (Lond) 244: 535548, 1975.

6) Ferguson, D.B. and Botchway, C.A.: Circadian variations in flow rate and composition of human stimulated submandibular saliva. Archs Oral Biol 24: 433-437, 1979.

7) Marcotte, H. and Lavoie, M.C.: Oral microbial ecology and the role of salivary immunoglobulin A. Microbiol Mol Biol Rev 62: 71-109, 1998.

8) Russell M.W., Hajishengallis, G., Childers, N.K. and Michalek, S.M.: Secretory immunity in defense against cariogenic mutans streptococci. Caries Res 33: 4-15, 1999.

9) Hucklebridge, F., Clow, A. and Evans, P.: The relationship between salivary secretory immunoglobulin A and cortisol: neuroendocrine response to awakening and the diurnal cycle. Int J Psychophysiol 31: 69-76, 1998.

10) Moore, R.Y. and Eichler, V.B.: Loss of a circadian adrenal corticosterone rhythm following suprachiasmatic lesions in rat. Brain Res 42: 201-206, 1972.

11) Shirakawa, T., Honma, S. and Honma, K.: Multiple oscillators in the suprachiasmatic nucleus. Chronobiol
Int 18: 371-387, 2001.

12) Lowry, O.H., Rosebrough, N.J., Farr, A.L. and Randall, R.G.: Protein measurement with the Folin phenol reagent. J Biol Chem 193: 265-275, 1951.

13) Campbell, I.T., Walker, R.F., Riad-Fahmy, D., Wilson, D.W. and Griffiths, K.: Circadian rhythms of testosterone and cortisol in saliva: effects of activityphase shifts and continuous daylight. Chronobiologia 9: 389-396, 1982.

14) Guechot, J., Fiet, J., Passa, P., Villette, J.M., Gourmel, B., Tabuteau, F., Cathelineau, G. and Dreux, C.: Physiological and pathological variations in saliva cortisol. Horm Res 16: 357-364, 1982.

15) Riad-Fahmy, D., Read, G.F. and Walker, R.F.: Salivary steroid assays for assessing variation in endocrine activity. J Steroid Biochem 19: 265-272, 1983.

16) Czeisler, C.A., Johnson, M.P., Duffy, J.F., Brown, E.N., Ronda, J.M. and Kronauer, R.E.: Exposure to bright light and darkness to treat physiologic maladaptation to night work. $N$ Engl J Med 322: 1253-1259, 1990.

17) Balsalobre, A., Brown, S.A., Marcacci, L., Tronche, F., Kellendonk, C., Reichardt, H.M., Schutz, G. and Schibler, U.: Resetting of circadian time in peripheral tissues by glucocorticoid signaling. Science 289: 2344-2347, 2000.

18) Kraehenbuhl, J.P. and Neutra, M.R.: Molecular and cellular basis of immune protection of mucosal surfaces. Physiol Rev 72: 853-879, 1992.

19) Nakamura, W., Honma, S., Shirakawa, T. and Honma, K.: Clock mutation lengthens the circadian period without damping rhythms in individual SCN neurons. Nat Neurosci 5: 399-400, 2002.

20) Rosato, R., Jammes, H., Belair, L., Puissant, C., Kraehenbuhl, J.P. and Djiane, J.: Polymeric-Ig receptor gene expression in rabbit mammary gland during pregnancy and lactation: evolution and hormonal regulation. Mol Cell Endocrinol 110: 81-87, 1995.

21) Legler, D.W., McGhee, J.R., Lynch, D.P., Mestecky, J.F., Schaefer, M.E., Carson, J. and Bradley, E.L. Jr.: Immunodeficiency disease and dental caries in man. Arch Oral Biol 26: 905-910, 1981.

22) Tenovuo, J., Grahn, E., Lehtonen, O.P., Hyyppa, T., Karhuvaara, L. and Vilja, P.: Antimicrobial factors in saliva: ontogeny and relation to oral health. J Dent Res 66: 475-479, 1987.

23) Mass, E., Gadoth, N., Harell, D. and Wolff, A.: Can salivary composition and high flow rate explain the low caries rate in children with familial dysautonomia? Pediatr Dent 24: 581-586, 2002.

24) Smith, D.J., Taubman, M.A. and Ebersole, J.L.: Ontogeny and senescence of salivary immunity. $J$ Dent Res 66: 451-456, 1987. 